\title{
Ignition and combustion of high-energy materials containing aluminum, boron and aluminum diboride
}

\author{
Alexander Korotkikh ${ }^{1,2, *}$, Ivan Sorokin ${ }^{1}$, and Ekaterina Selikhova ${ }^{1}$ \\ ${ }^{1}$ National Research Tomsk Polytechnic University, 634050 Tomsk, Russia \\ ${ }^{2}$ Tomsk State University, 634050 Tomsk, Russia
}

\begin{abstract}
Boron and its compounds are among the most promising metal fuel components to be used in solid propellants for solid fuel rocket engine and ramjet engine. Papers studying boron oxidation mostly focus on two areas: oxidation of single particles and powders of boron, as well as boroncontaining composite solid propellants. This paper presents the results of an experimental study of the ignition and combustion of the high-energy material samples based on ammonium perchlorate, ammonium nitrate, and an energetic combustible binder. Powders of aluminum, amorphous boron and aluminum diboride, obtained by the SHS method, were used as the metallic fuels. It was found that the use of aluminum diboride in the solid propellant composition makes it possible to reduce the ignition delay time by 1.7-2.2 times and significantly increase the burning rate of the sample (by 4.8 times) as compared to the solid propellant containing aluminum powder. The use of amorphous boron in the solid propellant composition leads to a decrease in the ignition delay time of the sample by a factor of 2.2-2.8 due to high chemical activity and a difference in the oxidation mechanism of boron particles. The burning rate of this sample does not increase significantly.
\end{abstract}

\section{Introduction}

Boron is one of the most promising metals for rocket fuels due to high specific combustion heat value (among the highest per unit of mass and the maximum possible per unit of volume [1]). However, its application is significantly complicated by the fact that inert layer of boron is formed on the surface of boron particles during storage and combustion. It prevents the access of oxidizer [2] to pure boron, significantly reduces the ignition time and combustion of particles [3].

Devoted to the investigation of boron oxidation processes articles are mainly represented in literature by three types of works: the study on the oxidation of single particles $[4,5]$ and boron powders [6-9], as well as boron-containing composite fuels [9, $10]$.

\footnotetext{
* Corresponding author: korotkikh@tpu.ru
} 
Numerous studies presented in literature on the characteristics of boron propellants ignition and combustion with different particle size [11], binder (most commonly used $\mathrm{NH}_{4} \mathrm{ClO}_{4}, \mathrm{KNO}_{3}$ ) and the ratio of fuel to oxidizer [12]. In studies aimed at studying ignition and combustion at high pressures [13] or under conditions close to real ones $[1,13]$ the conductive initiation (for example, heating with nichrome filament or hot gases in TGA chamber) was used. It was established that with an increase in the pressure and content of boron particles to 20 mass. \% in the fuel the linear burning rate and the surface temperature of the sample increase with the pressure dependence form close to linear [9].

Various techniques have been used to improve the characteristics of composite boronbased fuels. The one popular solution is using of coatings to prevent the formation of an oxide film, another is using bimetallic powders [10] with an ignition temperature of second metal lower than the evaporation temperature of the boron oxide film.

In this paper, we present the results of the experimental study of the ignition, combustion and corresponding surface temperature of the high-energy material samples based on ammonium perchlorate, ammonium nitrate and an energetic combustion binder with various types of boride powders. The study was carried out using a laser of continuous action.

\section{Experimental sections}

\subsection{Sample characterization}

Three HEM samples were used for ignition delay time and burning rate definition experiments. The first is the basic composition of HEM, containing $15 \mathrm{wt} . \%$ ammonium perchlorate (PCA) (fraction 160-315 $\mu \mathrm{m}$ ), $35 \mathrm{wt} . \%$ ammonium nitrate (NA) (fraction less than $100 \mu \mathrm{m}), 20$ wt.\% active fuel-binder MPVT-ASP and 30 wt.\% of metal fuel microsized aluminum powder ASD-4 with an average particle diameter $d_{43}=10.8 \mu \mathrm{m}$. Other two formulations of HEM aluminum powder is completely substituted by boron powders B $\left(d_{43}=2.0 \mu \mathrm{m}\right)$ and aluminum diboride $\mathrm{AlB}_{2}\left(d_{43}=6.2 \mu \mathrm{m}\right)$ obtained by the SHSmethod (self-propagating high-temperature synthesis).

\subsection{Experimental setup}

The HEM ignition process was carried out using setup based on the $\mathrm{CO}_{2}$ laser of continuous action with a wavelength of 10.6 microns and a maximum power of $200 \mathrm{~W}$ (Fig. 1). The diameter of the laser beam at the exit from the translucent mirror of the $\mathrm{CO}_{2}$ laser was approximately equal to the diameter of the sample. HEM samples were cut into $5 \mathrm{~mm}$ high tablets before the experiment. The flat end surface of the samples was visually monitored for the absence of pores, cavities and cracks.

The test sample (5) of the HEM was attached to the holder (6). When the shutter (3) was opened, exposure time $\sim 5 \mathrm{~ms}$, the heat flux was directed to the investigated HEM sample (5). The signals from the photodiodes (7) were transmitted through the L-card E-14-440 ADC (10) and recorded using personal computer (11), and then processed using the LGraph2 software. The ignition delay time $t_{i g n}$ of HEM was defined as a difference between the times of signal from photodiodes (7), one of which registered the occurrence of flame on the flat end surface of the sample. Relative error for delay time values $t_{\text {ign }}$ was $5-12 \%$ with confidence level 0.9 . 


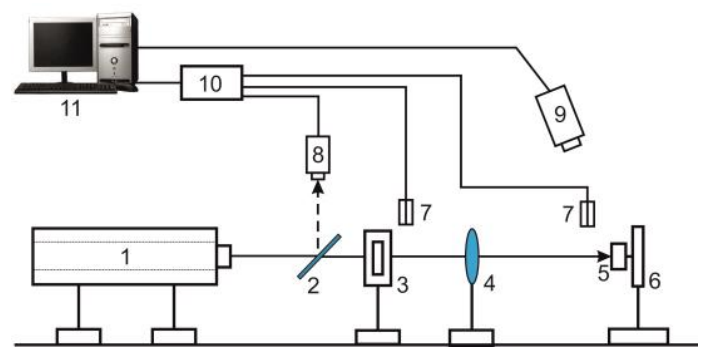

Fig. 1. The scheme of experimental setup based on $\mathrm{CO}_{2}$ laser: $1-\mathrm{CO}_{2}$ laser; 2 - beam-splitting mirror; 3 - shutter; 4 - lens; 5 - HEM sample; 6 - holder; 7 - photodiodes; 8 -thermoelectric sensor of radiation power; 9 - video camera; 10 - ADCs; 11 - PC.

The surface temperature of the fuel sample during the heating was recorded using a Jade J530 SB thermal imaging camera at a frequency of $50 \mathrm{~Hz}$ in the temperature range 370$1800{ }^{\circ} \mathrm{C}$. The thermal imaging data and the photodiode parameters were synchronized by a characteristic click produced by shutter opening. It corresponds to the beginning of the HEM sample heating.

The power of the laser radiation heat flux on the HEM sample was measured with a thermoelectric sensor Ophir FL400A (8). A maximum value of the radiation power at the center of the laser beam was determined through $2 \mathrm{~mm}$ diameter diaphragm. The ratio of the maximum value to the mean value over the area of the beam diameter of the radiation power was $\sim 1.7$.

\subsection{The burning rate}

The burning rate of the HEM was measured under atmospheric pressure. We used HEM with a diameter of $10 \mathrm{~mm}$ and a height of $25-30 \mathrm{~mm}$. The flat end surface of the samples was visually monitored for the absence of pores, cavities and cracks. The sample was placed on the holder and ignited with a nichrome spiral. The burning rate of the HEM was calculated from the known length of the sample and the burning time determined by the stopwatch.

\subsection{Activation energy calculation}

The activation energy value was determined by solving the inverse heat conduction problem of the heated by radiant flux sample according to the given in [14] method. It is based on the following equation:

$$
\lg \left(\frac{t_{i g n}}{\left(1-T_{0} / T_{i g n}\right)^{2}}\right)=\lg \left(\frac{0.359 \cdot E c}{(1-0.8 \cdot \beta) R \cdot Q z}\right)+\frac{E}{R T_{i g n}} \operatorname{lge},
$$

where $t_{i g n}$ - ignition delay time, $\mathrm{s} ; T_{0}$ - initial temperature of solid fuel sample, $\mathrm{K} ; T_{i g n}-$ quasistationary ignition temperature of the HEM sample surface, $\mathrm{K} ; E$ - effective activation energy of the reaction, $\mathrm{J} / \mathrm{mole} ; c$ - specific heat of the solid fuel sample, $\mathrm{J} /(\mathrm{kg} \mathrm{K})$; $\beta=\frac{R T_{i g n}}{E}-$ unitless parameter which expresses the degree of dependence of the reaction rate on temperature; $R$ - universal gas constant, $\mathrm{J} /($ mole $\mathrm{K}) ; Q$ - the thermal effect of the reaction, $\mathrm{J} / \mathrm{kg} ; z$ - reaction pre-exponent, $1 / \mathrm{s}$.

The value of the characteristic temperature can be determined by the following formula: 


$$
T_{i g n}=T_{0}+\sqrt{\frac{t_{i g n} \cdot(1-0.8 \cdot \beta)}{\lambda c \rho}} \cdot q,
$$

where $q$ - heat flux density, $\mathrm{W} / \mathrm{cm}^{2}, \lambda, \rho$ - thermal conductivity and density of the sample, $\mathrm{W} /(\mathrm{m} \cdot \mathrm{K})$ и $\mathrm{kg} / \mathrm{m}^{3}$.

\section{Results and discussion}

\subsection{Ignition delay time}

The dependence of the ignition delay times of solid fuel samples on the radiation flux density were obtained using setup for radiant heating. These dependences are shown in Fig. 2.

The graph in Fig. 2 shows that a complete replacement of the ASD-4 aluminum powder with boron powder results in a decrease in the ignition delay time of solid fuel samples by 2.2-2.8 times. The use of aluminum borides makes it possible to reduce the ignition delay time of fuels in comparison with the base composition by 1.7-2.2 times. An analysis of these results shows that the difference in the ignition delay time of the HEM during radiant heating is associated with oxidation reaction rate and chemical reaction heat during heating and ignition of the used metal additives.

The large values of $t_{i g n}$ for the basic composition containing aluminum ASD-4 are explained by the higher average diameter and the presence of a churlish oxide layer on the particles surface.

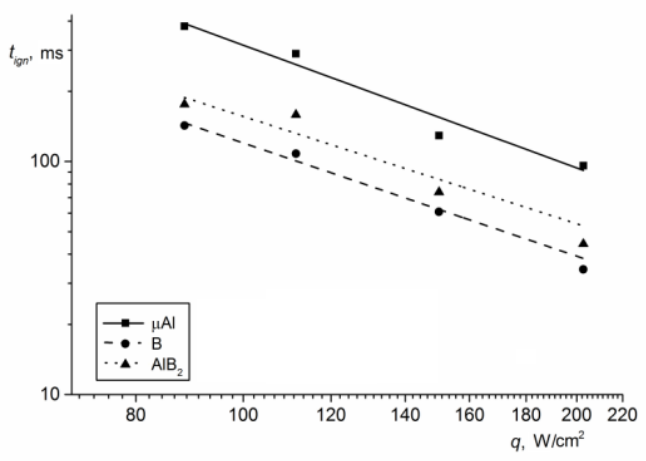

Fig. 2. HEM ignition delay time vs laser heat flux density: $\operatorname{tign}=9.90 \cdot 10^{5} q^{-1.75}-$ sample with $\mathrm{Al}$; $t_{\text {ign }}=2.02 \cdot 10^{5} q^{-1.61}-$ sample with B; $t_{i g n}=1.78 \cdot 10^{5} q^{-1.53}-$ sample with $\mathrm{AlB}_{2}$.

\subsection{Ignition temperature}

We obtained the synchronized video frames and thermal imaging corresponding to the main stages of ignition for the investigated samples. When processing the measured data, the temperatures on the reaction layer surface of HEM samples were obtained at a constant emissivity factor of 0.9 at the time of steady ignition (Table 1).

Table 1. Sample surface characteristic temperatures at the moment of ignition.

\begin{tabular}{|c|c|c|c|}
\hline Sample & $\mathrm{Al}$ & $\mathrm{B}$ & $\mathrm{AlB}_{2}$ \\
\hline Surface maximal temperature, ${ }^{\circ} \mathrm{C}$ & 1150 & 1260 & 1240 \\
\hline Surface average temperature, ${ }^{\circ} \mathrm{C}$ & 690 & 560 & 570 \\
\hline
\end{tabular}


It is worth mentioning, that the maximum surface temperatures of sample ignition with aluminum boride and amorphous boron powders are fairly close. This may indicate the leading role of particles $\mathrm{B}$ and $\mathrm{AlB}_{2}$ oxidation reaction during heating and ignition of HEM.

Fig. 3 shows the experimental maximum temperature values of the HEM surface as a function of the heating time. The heating and ignition process of the HEM can be divided into two stages differing in the rates of temperature increasing on the surface of the samples reaction layer. This can be caused by an increased rate of exothermic chemical reactions at higher decomposition temperatures of the oxidant, active fuel-binder and oxidation of metal particles.

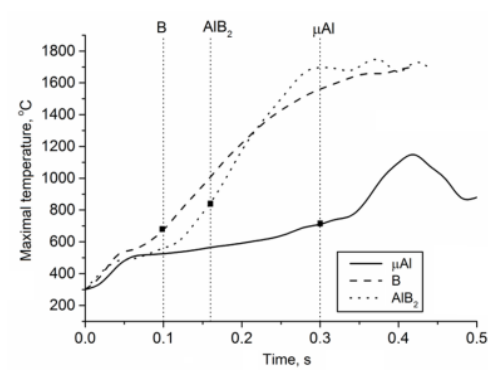

Fig. 3. Maximum surface temperature of the HEM samples as a function of the heating time.

\subsection{The burning rate}

We performed three parallel experiments for each of HEM samples and determined average values of the burning rate that is shown in Fig. 4.

Complete replacement of microsized aluminum powder ASD-4 with amorphous boron powder allows increasing the burning rate by 1.32 times. The burning rate of the HEM composition with aluminum diboride is 4.83 times higher than that for the base composition with ASD-4.

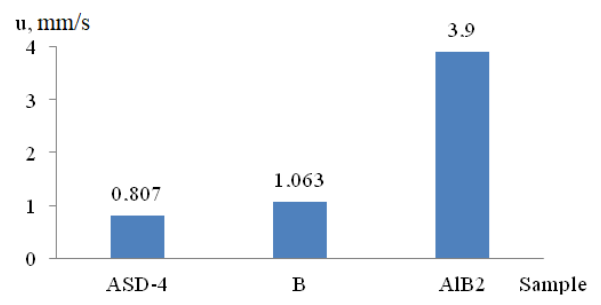

Fig. 4. Burning rate of HEM containing metal powder.

\subsection{Effective activation energy}

We determined the values of activation energy, reaction thermal effect, pre-exponent and characteristic ignition temperature of the HEM samples (Table 2). According to Table 2, samples with $\mathrm{Al}$ additive have the highest activation energy, while for samples with $\mathrm{AlB}_{2}$ it is the lowest. Based on these data it can be concluded that the addition of $\mathrm{AlB}_{2}$ into composition of HEM is preferred.

Table 2. Calculation results of kinetic parameters and ignition temperature of samples.

\begin{tabular}{|c|c|c|c|}
\hline Sample & $\mathrm{Al}$ & $\mathrm{B}$ & $\mathrm{AlB}_{2}$ \\
\hline$E, \mathrm{~kJ} / \mathrm{mole}$ & 159 & 90 & 74 \\
\hline$Q z, \mathrm{~W} / \mathrm{g}$ & $9.92 \cdot 10^{13}$ & $3.31 \cdot 10^{11}$ & $4.24 \cdot 10^{9}$ \\
\hline$T_{\text {ign }}{ }^{\circ} \mathrm{C}$ at $q=115 \mathrm{~W} / \mathrm{cm}^{2}$ & 846 & 641 & 687 \\
\hline
\end{tabular}




\section{Conclusions}

The paper presents an experimental study of ignition and combustion of the three solid fuel compositions based on perchlorate and ammonium nitrate, active binder and additives of metal powders $\mathrm{ASD}-4, \mathrm{~B}$ and $\mathrm{AlB}_{2}$. Ignition delay times, reaction layer surface temperature, ignition temperature, and linear burning rate under atmospheric pressure were determined. It is established that ignition delay times of HEM containing boron powder are 2.2 to 2.8 times smaller than the sample with aluminum ASD-4 in the heat flux density range of $90-200 \mathrm{~W} / \mathrm{cm}^{2}$. At the same time, the sample burning rate increased insignificantly (by 1.3 times) due to incomplete burning of boron and the heat released.

The use of aluminum diboride powder in the HEM composition allows to reduce the ignition delay time by 1.7-2.2 times in the indicated range $q$ and significant increase the burning rate (by 4.8 times) in comparison with HEM containing aluminum powder ASD-4 by increasing the efficiency and heat combustion of boron in the chemical reactions zone.

The reported study was supported by RFBR according to the research project No. 16-03-00630 a and by The Tomsk State University competitiveness improvement programme.

\section{References}

1. D. S. Sundaram, V. Yang, V. E. Zarko, CESW 51, 2 (2015)

2. W. Ao, Tz.-Kh. Zhou, Tz.-C. Liu, W.-Cz. Jan, Yu Wang, H.-R. Li, Phys. Combust. Explos. 50, 3 (2014)

3. K.-L. Chintersingh, M. Schoenitz, E. L. Dreizin, Combust. Flame 173, 288 (2016)

4. R. O. Foelsche, R. 1. Burton, H. Krier, Combust. Flame 117, 32 (1999)

5. J. Xi, J. Liu, Y. Wang, Y. Hu, Y. Zhang, J. Zhou, J. Propul. Power 30, 1 (2014)

6. J-Z. Liu, J-F. Xi, W-J. Yang, Y-R. Hu, Y-W. Zhang, Y. Wang, J-H. Zhou, Acta Astranaut. 96, 89 (2014)

7. L-J. Liu, G-Q. He, Y-H. Wang, J. Therm. Anal. Calorim. 114, 3 (2012)

8. V. Ao, T. Kh. Zhou, V. C. Yan, C. C. Liu, Yu. Wang, Phys. Combust. Explos. 50, 6 (2014)

9. T. Kuwahara, N. Kubota, Propellants Explos. Pyrotech. 14, 43 (1989)

10. A. G. Korotkikh, V. A. Arkhipov, O. G. Glotov, V. E. Zarko, A. B. Kiskin, Combust. Flame 178, 195(2017)

11. F. Maggi, A. Bandera, L. Galfetti, L. T. De Luca, T. L. Jackson, Acta Astronaut. 66, 1563 (2010)

12. V. A. Arkhipov, A. B. Kiskin, V. E. Zarko, A. G. Korotkikh, Combust. Explos. Shock Waves 50, 622 (2014)

13. T. L. Connell Jr., G. A. Risha, R. A. Yetter, C. W. Roberts, G. Young, J. Propul. Power 31, 1 (2014)

14. V. N. Vilyunov, V. E. Zarko, Ignition theory of condensed matter (EDP Science, Novosibirsk, 1984) 